\title{
Um uso muito particular do clitico se
}

\author{
A very specific use of the clitic se
}

Fernanda Beatriz Caricari de Moraes

Instituto Nacional de Educação de Surdos

Leila Barbara

Pontifícia Universidade Católica de São Paulo

Resumo: Neste artigo, analisa-se um conjunto de verbos cujo funcionamento ou significado varia quer ocorram com o clítico se ou não. A multiplicidade de funções, uma das características do se, é um dos problemas mais interessantes da língua portuguesa e de outras como francês, espanhol e italiano. Uma das controvérsias em torno desse clítico é a possibilidade do sujeito estar ou não indeterminado, como discutem as pesquisas de Nunes (1991), Monteiro (1994), Bagno (2000), Camacho (2002, 2003), entre outros. A base teórica, a Linguística Sistêmico-Funcional (HALLIDAY 1985, 1994; HALLIDAY; MATTHIESSEN, 2004), tem como foco a língua em uso e permite analisar as escolhas gramaticais em textos (escritos ou falados) com base no contexto de cultura e de situação em que se realizam. A partir das condições contextuais, o falante recorre às três metafunções da linguagem, das quais a que interessa, a este artigo, é a ideacional, responsável pelo uso da língua para falar sobre o mundo, tanto externo (coisas, eventos, qualidades, etc.), como interno (pensamentos, crenças, sentimentos, etc.). Pretende-se contribuir com os estudos sobre o uso desse clítico em língua portuguesa e, também, subsidiar a elaboração de materiais didáticos e desenho de cursos instrumentais que visam atender a produção e compreensão escrita.

Palavras-chave: Clítico se. Artigo científico. LinguísticaSistêmico-Funcional.

Abstract: This paper analyzes a group of verbs whose behavior or meaning change when used either with or without the clitic se. Its multiple functions, one of its features, is one of 
the most interesting problem in the Portuguese and other languages such as French, Spanish and Italian. One of the controversies about it is the possibility of the indeterminate Subject being (see NUNES, 1991; MONTEIRO, 1994; BAGNO, 2000; CAMACHO, 2002, 2003). Systemic Functional Linguistics (HALLIDAY 1985, 1994; HALLIDAY; MATTHIESSEN, 2004), the theory underlying this paper, focuses language in use and allows for the analyzis of grammatical

Fernanda

Beatriz

Caricari de

Moraes

Leila Barbara

\section{Introdução}

Este artigo se insere no projeto SAL (Systemics Across Languages), projeto internacional que tem como objetivo desenvolver pesquisas que descrevam inglês, francês, chinês, tailandês, português e espanhol, a partir do uso com base na Linguística Sistêmico-Funcional (Halliday $(1985,1994)$ e Halliday \& Matthiessen (2004)), que tem como foco a língua em uso e permite analisar as escolhas gramaticais do autor em textos (escritos ou falados) com base no contexto de cultura e de situação em que se realizam.

A partir das condições contextuais, o falante organiza seus textos recorrendo às três metafunções da linguagem, das quais, a que interessa a este trabalho é a ideacional, responsável pelo conteúdo da mensagem, o uso da língua para falar sobre o mundo, tanto externo (coisas, eventos, qualidades, etc.), como interno (pensamentos, crenças, sentimentos, etc.). Como salienta Thompson (1996, p. 76-77), o uso da linguagem reflete a visão de mundo do falante/escritor, ações/acontecimento (referidas nos verbos), participantes (substantivos), atributos (adjetivos) e circunstâncias de lugar, tempo, etc. (advérbios).

Trabalhos do SAL-Brasil se concentram em textos escritos, privilegiando discurso científico, quer de áreas especificas, quer comparando áreas, sempre partindo de textos; alguns exemplos de pesquisas já realizadas estão em Delta Especial (2011) e em outras publicações como: Autor1 (2010), Vivan (2010), Autor2 (2011), Sayão (2011) e Torres (2012).

Este artigo analisa um conjunto de verbos que aparentemente ocorrem em pequeno número, porém são muito usados e cujo funcionamento ou significado varia quer ocorram com o clítico se ou não. Pretende-se, com esta análise, contribuir para a descrição da língua portu- 
guesa e para o desenho de materiais didáticos que contribuam para o melhor entendimento da linguagem na prática escolar.

Para exemplificar o problema, compare-se os exemplos 1 a 4 abaixo:

1) A autonomia não se dá no âmbito da natureza reduzida ao em si de si mesmo... (25480). (está, acontece,está localizada)

2) Ele se deu bem na prova. (esteve, foi)

3) Paulo e Pedro se dão bem. (têm bom relacionamento entre sim; estão bem entre si)

4) Não dá para almoçarmos fora, os restaurantes já fecharam. (pode, é possível)

Um uso muito particular do clíticose

Nos exemplos 1 a 3 dar, acompanhado de se, se comporta como processo relacional, significado de ser/estar, podendo ter várias paráfrases semelhantes (em 1, está, acontece; 2 é uma oração recíproca, 3 equivale a ter ou estar bem), enquanto dar, em 4, corresponde a poder, ser possível também ligado ao auxiliar.

Halliday (1994, p. 121) discute casos, na língua inglesa, em que, do ponto de vista semântico, as construções são semelhantes, assim como as construções ( 1 a 4 ) acima, no entanto, do ponto de vista gramatical, elas são diferentes:

a) He's frightened. (relacional) Ele está assustado.

b) He's been frightened. (mental) Ele assustou-se.

Em A, o 's é o verbo be (ser) relacional e frightened (assustado) é um adjetivo de estado. Enquanto em $\mathrm{B}$, 's corresponde ao auxiliar have e frightened é o processo material ao qual o adjetivo está relacionado.

A relação que A e B estabelecem é de agnação (parentesco). Do ponto de vista gramatical, essas escolhas são diferentes, porém, do ponto de vista semântico, Halliday, acima, as denomina agnatas, ou seja, o fenômeno pode ser explicado não somente indicando como ele está estruturado, mas mostrando como ele está relacionado a outras funções da estrutura linguística, utilizando seu padrão de relações sistêmicas ou agnatas.

O conceito de agnato é importante para este artigo, pois permite explicar como um novo significado (relacional e/ou existencial) pode ser criado quando o clítico se ocorre, em determinados contextos e com certos tipos de verbos. Assim, as construções agnatas são metafóricas, ou ex- 
pressões não congruentes, contrastando com o modo congruente e comum de expressão. Para Halliday e Matthiessen (2004, p. 592), há uma escolha típica, no entanto, a língua pode fazer esses realinhamentos criando formas agnatas da mesma unidade semântica. Pode-se dizer que, na língua portuguesa, a agnação ocorre com um conjunto de verbos dos quais: dar, Fernanda encontrar, achar, fazer, manter, tratar, realizar, manifestar, estabelecer e tornar Beatriz ocorreram no corpus deste estudo que contém 1225 artigos científicos de

Caricari de

Moraes

Leila Barbara diversas áreas retirados da plataforma www.scielo.br, portal eletrônico que disponibiliza os periódicos brasileiros avaliados pelo Qualis ${ }^{1}$.

Esse corpus foi submetido ao programa WordSmith Tools (SCOTT, 2009), cuja a ferramenta mais usada é o Concordanciador, que organiza os dados a partir de um termo selecionado, permitindo o estudo sistemático dos diferentes contextos em que, nesta caso, o clítico se ocorre. Sabe-se que este clítico possui uma multiplicidade de funções e, por isso, é um dos problemas mais interessantes da língua portuguesa e de outras como francês, espanhol e italiano. A mais discutida controvérsia em torno desse clítico se refere à possibilidade do sujeito estar ou não determinado (NUNES (1991), Monteiro (1994), Bagno (2000) e Camacho (2002, 2003), o mesmo acontecendo com on em francês, se em espanhol e si em italiano, conforme trabalhos de Ruwet (1972), Suñer (2002) e Cinque (1988), respectivamente. No entanto, casos com o apontado neste trabalho, sobre o português, não apareceram na literatura pesquisada.

Desta forma, esta pesquisa parte da análise de textos reais para descrever o funcionamento de um clítico complexo da Língua Portuguesa, permitindo que verbos que atuam como processos materiais (fazer), mentais (pensar) ou verbais (dizer), sem o clítico se, quando acompanhados de se, adquirem significado relacional e/ou existencial. São, portanto, entradas lexicais diferentes. De acordo com a teoria Sistêmico-Funcional, uma unidade semântica pode ser realizada de diferentes formas, por unidades gramaticais distintas. É o que ocorre nas construções agnatas, foco da análise deste artigo.

\section{A Linguística Sistêmico-Funcional}

A Linguística Sistêmico-Funcional, (HALLIDAY - $(1985,1994)$ e Halliday

1. A nota Qualis é uma classificação feita pela CAPES dos veículos utilizados pelos programas de pósgraduação para a divulgação da produção intelectual de seus docentes e alunos, cujo objetivo é atender às necessidades específicas da avaliação da pós-graduação realizada por esta agência. 
e Matthiessen (2004)), hoje praticada em grande escala (MATTHIESSEN, 1995; MARTIN, 1992; EGGINS, 1994; CAFFAREL, 2006; THOMPSOM, 1996, entre outros), principalmente na Europa, Austrália, Oriente e contando com cada vez mais representantes na América Latina. É uma teoria sociossemiótica da linguagem que parte do significado para análise de suas representações linguísticas, para explicá-la em termos funcionais, na relação entre semântica e gramática, como aquela que constrói significados, como resume Matthiessen (1995, p. 7-8):

\footnotetext{
Grammatical categories are grammaticalizations of semantic ones; even categories such as Subject which have been claimed to be purely grammatical. (Such claims are reflection of one's approach to language, not of language itself.) In other words, both semantic and grammatical categories are categories of meaning... (MATTHIESSEN, 1995, p. 7-8).
}

Nessa abordagem, é preciso identificar as opções linguísticas, isto é, as possibilidades estruturais, lexicais e semânticas que o sistema linguístico oferece para o uso, explorando o significado de cada opção expressa. Thompson (1996) exemplifica essa perspectiva caracterizando-a como bottom up (de baixo para cima), das escolhas lexicais ao contexto.

O suporte teórico da teoria sistêmico-funcional, mais precisamente, a metafunção ideacional, permite compreender o uso da língua para falar sobre o mundo, tanto externo como interno e permite descrever e analisar os usos do se com o grupo de verbos encontrado no corpus de estudo, mostrando as diferenças de significado desses verbos nas orações com ou sem o clítico.

Constituído de processos, participantes e circunstâncias, o sistema da transitividade que constrói o mundo da experiência em um conjunto manipulável de tipos de processos: materiais (fazer, escrever, construir); mentais (pensar, imaginar, gostar) e relacionais (ser, estar, ter). Há, ainda, os processos comportamentais, manifestações de atividades psicológicas ou fisiológicas do ser humano; os processos verbais que representam os dizeres e, por fim, os existenciais que representam a existência de algo.

\section{Metodologia utilizada}

\subsection{0 corpus}

Conforme abordado na introdução deste artigo, utilizou-se o corpus do 


\section{Fernanda \\ Beatriz \\ Caricari de \\ Moraes \\ Leila Barbara}

projeto SAL formado por 1225 artigos científicos selecionados aleatoriamente da plataforma digital Scielo que contém revistas científicas de diversas áreas, distribuído conforme a Tabela 1, compilada a partir da ferramenta wordlist do programa WordSmith Tools v. 5 (Scott, 2008), usado também para fazer as concordâncias que permitem visualizar o contexto da palavra de busca se em todo o corpus.

\begin{tabular}{|l|l|}
\hline Textos & 1225 \\
\hline Total de palavras & 5.176 .335 \\
\hline Total de palavras diferentes & 118.411 \\
\hline No. De orações & 254.640 \\
\hline
\end{tabular}

Quadro 1: Características do corpus de estudo.

\subsection{Procedimentos de análise}

A organização dos dados para a análise foi feita a partir do levantamento das ocorrências do clítico se no concordanciador, eliminando as correspondentes a usos condicionais ou reflexivos e separando as demais. As ocorrências resultantes foram agrupadas para análise a partir de testes de significado, formando os refraseamentos ${ }^{2}$ possíveis: passiva, estativa, média, relacional (ser, estar, ficar) e oração existencial (haver, acontecer, ocorrer).

Para este trabalho, foram selecionadas as ocorrências que permitiram refraseamentos para construções do tipo relacional e/ou existencial, em que há mudança de significado com o uso do se, ou seja, ocorrências de verbos materiais, mentais ou verbais que quando ocorrem com o clítico tem seus significados alterados, conforme os exemplos discutidos na introdução deste artigo.

Dessa forma, a metodologia quantitativa é usada para servir de ponto de partida e complementar a análise qualitativa, baseada nos pressupostos da LSF, que procura ver o sistema linguístico em termos de sua função na sociedade, portanto entendê-los nos seus contextos para entender as preferências e os significados dos usos e das características das comunidades que as utilizam.

\section{Discussão e análise dos dados}

As ocorrências que permitem serem refraseadas para construções rela-

\footnotetext{
2. Termo utilizado para se referir às construções testes com significados próximos.
} 
cionais e/ou existenciais possuem significados distintos, em virtude de ocorrem com o se. São as com verbos materiais, mentais ou verbais que, quando ocorrem com o se, são responsáveis por formas agnatas. Halliday e Martin (1993, p. 71) já apontaram que certos verbos materiais, no discurso científico, se comportam, predominantemente, como relacionais. A forma agnata é usada para caracterizar elementos nominais como objetos de estudo e abstrações. Pode-se dizer que, na Língua Portuguesa, o clítico se parece ser um facilitador de construções agnatas, não só com o uso de verbos materiais com significados relacionais, mas também com mentais e verbais que podem ser utilizados com significado relacional, na caracterização ou avaliação de aspectos da pesquisa, ou ainda, com significado existencial, descrevendo processos da pesquisa através da representação de que algo existe ou acontece, recurso que

Um uso muito particular do clíticose permite o distanciamento do autor de seu texto.

\begin{tabular}{|c|c|c|c|c|c|c|c|c|c|c|c|c|}
\hline \multirow[b]{3}{*}{ Verbos } & \multicolumn{4}{|l|}{$-\mathbf{s e}$} & \multicolumn{8}{|l|}{+ se } \\
\hline & \multirow[b]{2}{*}{$\begin{array}{l}\frac{\pi}{2} \\
\frac{\pi}{d} \\
\sum^{\pi}\end{array}$} & \multirow[b]{2}{*}{ 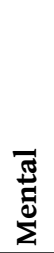 } & \multirow[b]{2}{*}{$\begin{array}{l}7 \\
\text { ?0 } \\
0 \\
0\end{array}$} & \multirow[b]{2}{*}{ 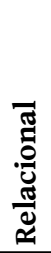 } & \multicolumn{4}{|c|}{ Relacionais } & \multicolumn{4}{|c|}{ Existenciais } \\
\hline & & & & & $\dot{\bar{D}}$ & 营 & 芯 & 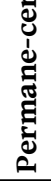 & 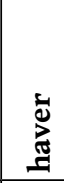 & 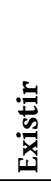 & 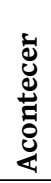 & 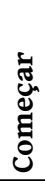 \\
\hline Encontrar & $\mathrm{X}$ & & & & & $\mathrm{X}$ & & & $\mathrm{X}$ & $\mathrm{X}$ & & \\
\hline Achar & $\mathrm{X}$ & $\mathrm{X}$ & & & & $\mathrm{X}$ & & & & & & \\
\hline Fazer & $\mathrm{X}$ & & & & $\mathrm{X}$ & $\mathrm{X}$ & & & & & & \\
\hline Manter & $\mathrm{X}$ & & & & & & & $\mathrm{X}$ & & & & \\
\hline Dar & $\mathrm{X}$ & & & & & $\mathrm{X}$ & & & & & $\mathrm{X}$ & \\
\hline Tratar & $\mathrm{X}$ & & $\mathrm{X}$ & & $\mathrm{X}$ & & & & & & & \\
\hline Realizar & $\mathrm{X}$ & & & & & & & & & & $\mathrm{X}$ & \\
\hline Manifestar & $\mathrm{X}$ & & $\mathrm{X}$ & & & & & & & & $\mathrm{X}$ & \\
\hline Estabelecer & $\mathrm{X}$ & & & & & & & & & & $\mathrm{X}$ & \\
\hline Tornar & $\mathrm{X}$ & & & & & & $\mathrm{X}$ & & & & & \\
\hline Apresentar & $\mathrm{X}$ & & $\mathrm{X}$ & & $\mathrm{X}$ & & & & & & & \\
\hline Mostrar & $\mathrm{X}$ & & & & $\mathrm{X}$ & & & & & & & \\
\hline Ter & & & & $\mathrm{X}$ & & & & & $\mathrm{X}$ & & & \\
\hline
\end{tabular}

Quadro 2: Resumo dos verbos que ocorrem em construções agnatas com se.

Nota-se que todos os verbos listados funcionam como materiais 
Fernanda

Beatriz

Caricari de

Moraes

Leila Barbara

238 sem o clítico se, alguns, além de materiais, também possuem significado verbal, como é o caso de tratar, manifestar e apresentar. O verbo achar possui significado material e mental. No entanto, quando esses verbos ocorrem com o clítico se, em certos contextos, podem funcionar como um tipo de processo, como é o caso de tratar, que possui significado de ser, achar com significado de estar, manter com significado de permanecer, tornar com significado de ficar, realizar, manifestar e estabelecer que ocorrem com significado de acontecer e, por fim, os verbos apresentar e mostrar com significado de ser.

A análise desses verbos é feita por grupos de semelhança de acordo com os significados relacionais e existenciais que esses adquirem quando ocorrem com se, levando em conta seus contextos de uso e as seções onde ocorrem nos artigos científicos. Dessa forma, optou-se por organizar esta análise seguindo os significados relacionais mais ocorrentes - o ser, seguido de estar, ficar e permanecer. Em seguida, são tratados os significados existenciais - acontecer/ ocorrer e haver/existir.

\subsection{Agnatos com se com significado de ser}

Neste subitem, são analisadas construções que quando ocorrem com o clítico se adquirem significado relacional de ser, como no exemplo abaixo:

Trata-se de uma máquina confeccionada em fibra de vidro capaz de imobilizar ou abater crustáceos imersos em água doce ou salgada, à temperatura ambiente. (encaos).

Tratar não tem significado material (cuidar), nem verbal (falar), mas relacional: é uma máquina confeccionada em fibra de vidro... Este fenômeno acontece com os verbos apresentados no Quadro 3.

\begin{tabular}{|c|c|c|c|c|c|c|c|c|c|c|}
\hline \multirow{2}{*}{ Verbo } & \multicolumn{2}{|c|}{$\begin{array}{l}\text { Existen- } \\
\text { ciais }\end{array}$} & \multicolumn{2}{|c|}{$\begin{array}{l}\text { Relacio- } \\
\text { nais }\end{array}$} & \multicolumn{2}{|c|}{ 2(E e R) } & \multicolumn{2}{|c|}{$\begin{array}{l}\text { Desfoca- } \\
\text { mento }\end{array}$} & \multicolumn{2}{|l|}{ Total } \\
\hline & $\mathbf{N}$ & $\%$ & $\mathbf{N}$ & $\%$ & $\mathbf{N}$ & $\%$ & $\mathbf{N}$ & $\%$ & $\mathbf{N}$ & $\%$ \\
\hline Tratar & 0 & 0 & 1152 & 98,5 & 0 & 0 & 17 & 1,5 & 1169 & 100 \\
\hline Apresentar & 0 & 0 & 666 & 91,5 & 0 & 0 & 60 & 8,5 & 726 & 100 \\
\hline Mostrar & 0 & 0 & 589 & 98 & 0 & 0 & 13 & 2 & 602 & 100 \\
\hline Dar & 225 & 45 & 4 & 0,5 & 145 & 29 & 127 & 25,5 & 501 & 100 \\
\hline Fazer & 0 & 0 & 180 & 39 & 0 & 0 & 282 & 61 & 462 & 100 \\
\hline
\end{tabular}




\begin{tabular}{|l|l|l|l|l|l|l|l|l|l|l|}
\hline Total & 225 & 6,5 & 2591 & 75 & 145 & 4 & 499 & 14,5 & 3460 & 100 \\
\hline
\end{tabular}

Quadro 3: Agnatos com se e significado de ser.

No Quadro 3, os significados, representados pelas colunas verticais, mostram o uso em construções: existenciais, relacionais, com os dois tipos, existencial e relacional - 2 (E e R) e, por fim, construções ligadas ao fenômeno desfocamento, discutido na tese que pesquisou os usos do se como recurso de impessoalização na escrita acadêmica (Autor, 2013). Como se pode observar, o verbo dar é o único que também ocorre, no corpus de estudo, com significado existencial, por isso ele é discutido neste subitem e, também, no item referente aos significados de acontecer/ocorrer.

As ocorrências em que os verbos adquirem significado de ser são Um uso muito particular do clítico se utilizadas, em geral, para definir aspectos da pesquisa tanto ligados aos objetos de estudo, como aos objetivos de pesquisa. Os verbos que ocorrem com esse significado são: tratar, dar, mostrar e fazer.

As construções do verbo tratar, acompanhadas de se, não têm significado material (cuidar, alimentar, por exemplo), mas sim relacional, por isso são agnatas. Nas ocorrências abaixo, tratar é utilizado para definir o trabalho desenvolvido:

1) Trata-se, na verdade, de uma análise, dentro do arcabouço teórico gerativo, das propriedades sintáticas destes verbos, antes tratadas de maneira dispersa e não como subcategoria coerente e estruturalmente significativa dos verbos intransitivos. (Idg103).

2) Trata-se, em linhas gerais, de uma tentativa de complexificar os pontos de vista científico e analítico-interpretativo... (25458).

3) Trata-se de uma proposta para a solução de problemas causados pelo acúmulo de rejeitos contendo metais pesados, principalmente cádmio, chumbo e zinco, resultantes das operações da Companhia. (enmaps).

4) Trata-se de um recorte nos resultados de pesquisa realizada em Maranguape, a $27 \mathrm{~km}$ da capital do Ceará... (m.amb58).

Nessas construções, o verbo é seguido de nomes, possui participante (Identificador) recuperável no contexto e, em geral, corresponde ao trabalho, ao artigo e à pesquisa. A relação dos participantes, estabelecida nessas orações, é Identificador e Identificado, que corresponde a uma 
análise, uma tentativa, uma proposta e um recorte nos resultados de pesquisa. Por serem orações identificadoras, a ordem dos participantes pode ser alterada, sem alteração do significado.

Além do significado relacional possibilitado pelos refraseamen-

Fernanda

Beatriz

Caricari de

Moraes

Leila Barbara

240

tos com ser sem alteração do significado, é possível, também, refrasear com haver e ter significados existenciais, conforme pode-se observar:

1'. [O trabalho] é, na verdade, uma análise, dentro do arcabouço teórico gerativo...

1". Há, na verdade, uma análise, dentro do arcabouço teórico gerativo...

A diferença entre essas duas construções é a relação entre os participantes, enquanto em 1', há a relação entre Identificador e Identificado, em 1" há apenas um único participante, o Existente. A oração relacional retoma um participante (trabalho) que foi mencionado anteriormente, enquanto a construção existencial representa que algo existe ou acontece. Apesar da possibilidade existencial, o significado original não é mantido, em 1" é representa a existência de uma análise dentro do arcabouço teórico gerativo e não que o trabalho de um determinado autor, que pode ser recuperado no contexto anterior, é análise dentro do arcabouço teórico gerativo. Essa última construção permite fazer a avaliação de algo, não só mostrando a existência.

É importante observar que os participantes das orações relacionais, assim como existenciais, não possuem caráter de Agente ou de Objeto, ou seja, um participante não está agindo sobre outro, por isso não há aquele que faz e nem aquele a quem se faz. A relação, no caso dessas ocorrências, é y é identificado por $x$. Se fosse uma relação atributiva, seria y é um atributo de x, conforme explica Halliday e Matthiessen (2004, p. 216).

As construções com tratar são usadas também na definição de conceitos teóricos nas resenhas teóricas do artigo de pesquisa, conforme as ocorrências:

5) A seu respeito, Robert Martin (1972:21) nos diz que [partícula negativa ne do francês] se trata de um morfema que .... (Idg070).

6) O que Hegel ensina é que [pertencimento] se trata de uma relação onde a identidade de um se perfaz pela identidade do outro... (enc029). 
7) Se é verdade que a economia não dispensa um fundamento ético, a tese de Dumont sustenta que se trata de uma base que reforça o caráter autônomo da ciência econômica... (25373).

Assim como as ocorrências anteriores, as acima são construções identificadoras, os Identificados estão entre colchetes por estarem em períodos anteriores ou estão grifados quando estão no mesmo período.

O verbo dar, quando ocorre com se, não tem significado material (oferecer, entregar, pagar, por exemplo), e sim relacional, também utilizado na definição de aspectos teóricos, conforme exemplos abaixo:

8) A autonomia não se dá no âmbito da natureza reduzida ao em si de si mesmo, ou seja, enclausurada numa existência determinada. (25480).

Um uso muito particular do clíticose

9) Na escrita, a interação dá-se com um sujeito potencialmente ausente.... (Idg018).

10) A sistematização de classificação industrial dá-se segundo uma ou mais características dos bens e serviços produzidos... (econ1).

Nos exemplos acima, as construções, com significado de ser, são utilizadas para definir aspectos estudados no artigo, mas as construções com dar podem descrever também aspectos metodológicos da pesquisa, como se pode observar nas construções abaixo:

11) Essa eliminação dá-se por um mecanismo de checagem, que consiste no apagamento de traços não interpretáveis... (Idg097).

12) A recategorização dessa ordem se dá, por exemplo, quando a relação entre dois (ou mais) referentes é do tipo todo-parte... (Idg016).

Nos exemplos acima, as etapas metodológicas representadas por nominalizações em posição de sujeito (monitoramento, eliminação e recategorização) são usadas em descrições de procedimentos na seção materiais e métodos ou metodologia. Nota-se que o uso da preposição por parece facilitar também a interpretação existencial (ocorrer) nas construções - aspectos que são discutidos no subitem significados de ocorrer/acontecer ligados à interpretação existencial.

O verbo fazer (com o clítico se) não é utilizado como material, como sinônimo de criar, fabricar, por exemplo. É utilizado como rela- 
Fernanda

Beatriz

Caricari de

Moraes

Leila Barbara

242

cional (ser) em avaliações, mais especificamente, quando ocorre acompanhado de necessário, preciso e possível, formando uma modalidade objetiva explícita. Fazer + necessário é a formulação mais frequente com $81 \%$ das ocorrências relacionais e está relacionada à modulação como papéis de atuação que implicam em obrigação ou inclinação.

Ao usar construções como as abaixo, o autor parece expressar sua opinião de uma forma mais empacotada do que é necessário e, ainda, mais empacotada que eu acho necessário que.... Este recurso, ligado à impessoalidade exigida pelo gênero artigo científico, faz com que a construção metafórica seja preferida à mais congruente. As construções com fazer estão ligadas à modulação que implica em obrigação:

13) Faz-se necessário que a abordagem pedagógica vá um pouco mais além e enfoque também a questão da transparência ilocucionária e marcação pragmática... (Idg086).

14) Faz-se necessário assim mostrar que a cura na clínica lacaniana é indissociável de um movimento de subjetivação... (25473).

15) Se o crime oferece vantagens a jovens sem perspectivas, sem esperanças e sem adolescência, faz-se necessária a criação de condições para que ao menos as mesmas vantagens de recuperação da auto-estima... (25368).

As ocorrências acima mostram o posicionamento do autor por meio do uso da modulação. $\mathrm{O}$ uso de faz-se necessário (a) com verbos pospostos é frequente nos dados. Destaca-se o 16 que, em vez do verbo posposto como nos anteriores, traz uma nominalização (criação) que, para Halliday (1994) e Halliday e Mattiessen (2004), é um recurso utilizado para condensar informação de maneira altamente estruturada, uma construção da gramática funcional que é chave para o entendimento da natureza dos registros acadêmicos. É a expressão de conceitos em uma forma não-congruente.

Nessas ocorrências, o autor mostra seu posicionamento de maneira objetiva nas discussões do artigo científico, podendo se dirigir à área de trabalho, como as duas primeiras (14 e 15) com o posicionamento do autor sobre aspectos das áreas educação e psicologia, respectivamente. Podem também exprimir opinião sobre as ações do governo de maneira geral (16). 
Pode-se pensar que o autor partilha esses questionamentos com o leitor de seu artigo, como uma forma de introduzir a discussão ou, ainda, argumentar para convencê-lo a partilhar da mesma ideia.

A utilização do verbo mostrar com o se também envolve contextos avaliativos, como se pode observar nas ocorrências a seguir:

16) O tubo de esperma mostrou-se repleto de espermátides e espermatozóides agrupados... (25410).

17) A banda em $3446 \mathrm{~cm}-1$ mostra-se bem menos intensa, devido à ausência quase total de água entre suas lamelas. (pol.6).

18) Esse resultado mostra-se semelhante ao encontrado no presente estudo, exceto para a maior quantidade de espécies da família Myrtaceae. (c.bio6).

Um uso muito particular do clíticose

Nas ocorrências acima, é possível notar um significado menos assertivo, utilizado para caracterizar os resultados obtidos na pesquisa. As construções abaixo foram refraseadas para discutir os diferentes significados:

19'. Esse resultado é semelhante ao encontrado no presente estudo...

19". Esse resultado parece ser semelhante ao encontrado no presente estudo...

A construção 19' não deixa dúvidas na avaliação, descreve o resultado da pesquisa com precisão. Enquanto em 19" o significado não é assertivo, o modal pode dá a construção um sentido de possibilidade. Ao optar por uma construção assim, o autor deixa de ser categórico e assertivo, se preserva através da representação de uma possibilidade, deixando o discurso mais polido, característico da linguagem científica.

As ocorrências de mostrar acompanhado de se são, em geral, orações atributivas e ocorrem frequentemente na parte final dos artigos, em especial, nas seções discussão dos resultados e conclusão, como se pode observar nas ocorrências 17 a 19.

As construções com apresentar acompanhadas de se possuem usos semelhantes às construções do verbo mostrar. Também ocorrem no corpus com significado relacional, não importando o tempo verbal: 
19) O tempo de tratamento apresentou-se significativamente maior para o grupo que utilizou o aparelho Pendulum... (odrdp15.6).

20) Como pode ser observado, o filme obtido se apresenta homogêneo, compacto, com estrutura globular. (pol6).

Fernanda

Beatriz

Caricari de

Moraes

Leila Barbara

244

21) Diferentemente, em relação às coletas mensais, os números de C. ribeirensis apresentaram-se significativos ( $p$-valor $=0,001$ ). (c.bio12).

O significado de apresentar, nas ocorrências acima, é relacional (parece ser) e as orações atributivas são utilizadas para caracterizar e avaliar os resultados, nas seções discussão dos resultados ou conclusão.

Além de avaliar os resultados obtidos, as construções com mostrar também são utilizadas para avaliar o método usado na pesquisa:

22) O paralelismo formal mostrou-se significativo na análise, sendo selecionado em primeiro lugar em todas as subamostras. (Idg083).

23) A metodologia utilizada mostrou-se bastante útil para classificar os genótipos segundo suas produtividades e seus padrões de resposta...(25909).

24) O software IDRISI mostrou-se ferramenta adequada e eficiente na avaliação da cobertura proporcionada pela pulverização na superfície vegetal estudada. (25863).

Através do uso dos atributos: significativo, bastante útil e ferramenta adequada e eficiente, a metodologia ou as ferramentas metodológicas são bem avaliadas pelos seus pesquisadores.

\subsection{Agnatos com se com significado de estar}

Neste subitem, são analisadas as construções em que certos verbos quando ocorrem com o clítico se possuem significado de estar. As orações com achar, por exemplo, quando ocorrem com esse clítico não têm significado material, sinônimo de encontrar e nem mental, sinônimo de pensar, mas sim relacional, com significado de estar: "Este modo de pensamento se acha livre do "princípio de realidade" e está em relação direta com o "princípio de prazer". (25430)".

Além de achar, os verbos encontrar e fazer também têm significado relacional de estar quando ocorre com o clítico se em determinados contextos, 
conforme o Quadro 4.

\begin{tabular}{|l|l|l|l|l|l|l|l|l|l|l|}
\hline \multirow{2}{*}{ Verbo } & \multicolumn{2}{|l|}{ Existenciais } & \multicolumn{2}{|l|}{ Relacionais } & \multicolumn{2}{|l|}{ 2(E e R) } & \multicolumn{2}{l|}{ Desfocamento } & \multicolumn{2}{l|}{ Total } \\
\cline { 2 - 12 } & $\mathbf{N}$ & $\mathbf{\%}$ & $\mathbf{N}$ & $\mathbf{\%}$ & $\mathbf{N}$ & $\mathbf{\%}$ & $\mathbf{N}$ & $\mathbf{\%}$ & $\mathbf{N}$ & $\mathbf{\%}$ \\
\hline Encontrar & 0 & 0 & 662 & 91,3 & 46 & 6,3 & 18 & 2,5 & $\mathbf{7 2 6}$ & $\mathbf{1 0 0}$ \\
\hline Fazer & 0 & 0 & 180 & 39 & 0 & 0 & 282 & 61 & $\mathbf{4 6 2}$ & $\mathbf{1 0 0}$ \\
\hline Achar & 0 & 0 & 86 & 78 & 0 & 0 & 24 & 22 & $\mathbf{1 1 0}$ & $\mathbf{1 0 0}$ \\
\hline Total & $\mathbf{0}$ & $\mathbf{0}$ & $\mathbf{9 0 4}$ & $\mathbf{7 1 , 5}$ & $\mathbf{4 6}$ & $\mathbf{3 , 5}$ & $\mathbf{3 1 8}$ & $\mathbf{2 5}$ & $\mathbf{1 2 6 8}$ & $\mathbf{1 0 0}$ \\
\hline
\end{tabular}

Quadro 4: Agnatos com se e significado de estar

Como se pode observar, somente o verbo encontrar possui significado existencial (haver/existir), os demais ocorrem no corpus com significado de estar. Esses três verbos são usados para caracterizar uma situação de momento, o que permite fazer constatações ligadas aos objetos de estudo, às metodologias utilizadas e aos resultados obtidos. Ao contrário do grupo anterior - significados de ser, em que o verbo define, o grupo dos significados de estar representa o ser em um dado momento.

Essas orações são utilizadas para fazer descrições, atribuindo características a uma entidade, conforme ocorrências:

25) Diversos moradores do bairro do Barracão pedem-nos reclamemos atenção a quem de direito para o verdadeiro estado de abandono em que se acha parte do Município. (25204).

26) Em outras palavras, em princípio, ao referir, ao ativar e reativar determinado referente, o autor pode inserir na progressão referencial um ponto de vista único, particular, subjetivo, situado contextualmente. Esse fenômeno acha-se no excerto abaixo. (Idg016).

27) Na mesma comissão estava presente, também, o deputado Andrade Figueira, um dos principais debatedores do projeto quando este ainda se achava na Assembléia Geral. (25348).

Nos exemplos acima, as orações atributivas são utilizadas para descrever e avaliar aspectos tratados nos artigos, representados pelos Portadores (explicação, fenômeno, parte do Município e projeto). Nota-se que os Atributos dos exemplos 27 e 28 são do tipo circunstancial (x está em 
$\begin{array}{r}\text { Fernanda } \\ \text { Beatriz } \\ \text { Caricari de } \\ \text { Moraes } \\ \text { Leila Barbara } \\ \hline 246\end{array}$

a), em que estar em significa estar em, sobre, para com, acerca, ao longo, etc. As demais ocorrências que possuem significado de estar também são orações atributivas:

28) A opção pelo modelo de Dik justifica-se no fato de ser esse autor pioneiro na tentativa de propor uma teoria funcional completa, que, entretanto, ainda se acha em fase de elaboração. (Idg089).

29) Este modo de pensamento se acha livre do "princípio de realidade" e está em relação direta com o "princípio de prazer". (25430).

30) Nessa perspectiva, antes da criação do EFG a doação não se achava onde mais se falava dela, mas sim entre os próprios profissionais...(25276).

Assim como os exemplos acima que estabelecem relação entre duas entidades (Portador-Atributo), descrevendo aspectos estudados e discutidos nos artigos, parte das ocorrências com fazer (19\%) também é usada dessa forma:

31) Contudo, a ofensiva da burguesia contra a classe trabalhadora fez-se presente como no passado... (econ012).

32) Essa autoridade faz-se presente na noção de identidade como instável e como processo, ao invés de entidade, nas teorias de representação de Hall (1997), ou na teoria pós-colonial de Bhabha (1994).... (Idg105).

33) É essa acepção que se faz presente no conceito moderno de sociedade, na qual reina a unidade muda, consenso anônimo, opinião única... (25482).

A maioria das ocorrências de encontrar, com se, é de construções relacionais (estar). Seus usos estão ligados à caracterização e avaliação dos resultados obtidos na pesquisa, como mostram as ocorrências abaixo:

34) Encontramos um p-valor $=0,021484$, isto é, o resultado se encontra na região de rejeição. (Idg026).

35) Esse resultado encontra-se de acordo com o obtido por Barros3, que verificou - em uma amostra homogênea em relação ao tipo e à severidade inicial da má oclusão - que a realização de extrações de dois pré-molares superiores... (od_v15_6).

36) Dos resultados mostrados na Figura 2 observa-se que à medida que a solução é exposta ao LED, a intensidade da luz provenien- 
te da solução diminui em toda faixa de comprimento de onda investigado, e o pico de máxima intensidade, que se encontra inicialmente em torno de $500 \mathrm{~nm}$. . (pol.12).

Ao usar o clítico com o processo encontrar, os autores avaliam os resultados obtidos na pesquisa, descrevendo-os sem se representarem nos artigos. A diferença de significado de encontrar com e sem o se pode ser observada no exemplo 35, em que encontrar na primeira oração tem significado de achar, descobrir (material) e o p-valor é a Meta. Em encontramos um p-valor=0,021484, o Ator (nós) age sobre a Meta, diferente da relação estabelecida na segunda oração - o resultado se encontra na região de rejeição, em que o significado do processo encontrar é estar, representa uma característica/avaliação do resultado.

Orações atributivas também são utilizadas para descrever os procedimentos ou materiais utilizados na pesquisa:

37) Este regime térmico se encontra na faixa de temperatura na qual a maior parte das sementes nativas estudadas germina... (cbio6).

38) Nela, fica evidenciado que a baixa difusividade térmica do material do molde fabricado em compósito epóxi/alumínio decorre dos baixos valores de condutividade térmica, que para a maioria dos materiais poliméricos encontra-se na faixa de 0,1-0,4 W/ $\mathrm{m} \times \mathrm{K}$... (pol4).

39) O Jasper Jumper [aparelho] encontra-se disponível em 7 diferentes comprimentos... (od146_5).

Essas orações possuem, em geral, Portadores que remetem a procedimentos ou equipamentos característicos da área de pesquisa que o artigo pertence, fazem parte da seção materiais e métodos ou metodologia.

Os verbos analisados acima, com significado de estar, também são utilizados em construções estativas - estar + verbo no particípio passado. Nestas construções, não há possibilidade de se ter um Agente, pois ele está suprimido, não sendo admissível, podendo gerar uma oração não aceita pela gramática, segundo Givón $(1981 ; 1994)$. Em termos sistêmicos, pode-se dizer que nas construções estativas, o participante (Ator, Dizente ou Experienciador, por exemplo) está suprimido. As estativas assemelhamse às existenciais, pois possuem apenas um participante na oração:

40) Adotamos a distinção feita por Van Valin e LaPolla (1997) entre as 
Fernanda

Beatriz

Caricari de

Moraes

Leila Barbara

hierarquias de acessibilidade nas línguas nominativo-acusativas e nas absolutivo-ergativas, às quais adicionamos a função de Recipiente. $O$ resultado acha-se exposto na Tabela 10:... (Idg008).

41) Já os pacientes paraibanos demonstraram um maior interesse no tratamento cirúrgico (facial) deste caso do que seus respectivos profissionais, o que é perfeitamente compreensível, em se tratando de um caso cuja proeminência nasal parece responder por boa parte da convexidade facial e a oclusão geralmente se encontra compensada nestes casos (Quadro 4). (odrdp003).

42) O município de Araruna encontra-se situado a 230 55' de Latitude Sul e a 520 30' de longitude Oeste de Greenwich, com altitude média de 660 m. (25843).

Como se pode observar, os verbos achar e encontrar têm significado de estar e são acompanhados de verbos no particípio passado indicando um estado. Apesar do significado de estar, essas orações diferem das relacionais descritas anteriormente nesta análise, utilizadas para caracterizar, avaliar objetos de estudo, metodologias e resultados obtidos. Em 41, 42 e 43 se têm construções estativas que, assim como as existenciais, descrevem um estado de existência. Os tipos de circunstâncias usadas nas orações acima também se assemelham às usadas nas orações existenciais - circunstâncias de lugar.

Ao fazer uso de orações estativas, os autores dos artigos optam por descrever os resultados (como em 41 e 42) ou descrever algo (como o município de Araruna, em 43), sem representar uma ação que implica na participação de um Agente.

\subsection{Agnatos com se com significado de ficar}

O verbo tornar é o único que ocorre com significado de ficar no corpus desta pesquisa, totalizando 962 ocorrências com significado unicamente relacional. o significado de ficar marca uma mudança, algo que passou a ser diferente na área de estudos, ou até mesmo na própria pesquisa.

O verbo tornar ocorre acompanhado de necessário/necessária em $11,5 \%$ das ocorrências e seu uso com o clítico se não pode ser considerado modalidade objetiva explícita, como ocorre com o verbo fazer, como se observou em casos anteriores, que também acompanhavam necessário/necessária, pois não se trata de uma opinião "disfarçada", mas 
uma mudança, algo que era de uma forma passou a ser de outra, como mostram os exemplos:

43) Torna-se necessário refletir sobre esse fenômeno social brasileiro e extrair as suas consequências para o trabalho dos professores. (meioamb17).

44) Assim, torna-se necessário entender a distribuição de reservas entre as diferentes partes desses dois grupos de plantas.... (encaor).

45) ... torna-se necessário averiguar quais os critérios de seleção exigidos por esta definição do objeto da história.... (25478).

Essas ocorrências foram retiradas das introduções dos artigos e as mudanças, representadas pela construção torna-se necessário, são Um uso muito particular do clítico se

usadas para representar a importância do estudo que é feito no artigo, como uma justificativa.

A maioria das ocorrências de tornar $(88,5 \%)$ é acompanhada de outros atributos como os abaixo:

46) Entretanto, a utilização de contrastes com essa finalidade tornase trabalhosa à medida que o número de tratamentos aumenta. (25657).

47) Dos 10 aos 13 anos, a contribuição dos meninos era de $15 \%$ e a das meninas, $12 \%$, diferença que se torna significativa dos 14 aos 17 anos quando a contribuição dos meninos passava para $21 \%$ e a das meninas para $17 \%(\mathrm{p}<0,001)$. (econ 47$)$.

48) Se ainda por cima se acrescentam estruturas de subjetividade em relação ao gênero ou à raça, então o modelo se torna complicado demais para ser controlado. (25363).

49) Em geral, ela [a incineração] se torna economicamente inviável, quando adotada apenas para essa finalidade. (meioamb34).

Construções como as acima, com tornar + atributo, são utilizadas para avaliar aspectos discutidos e/ou trabalhados na pesquisa, podendo ser um método (em 47 e 48), resultados (em 49) e estudos precursores (50). Destaca-se o uso de nominalizações nas primeiras orações, como: a utilização, a contribuição e incineração, utilizadas para condensar informação. 


\subsection{Agnatos com se com significado de permanecer}

As construções desse grupo compartilham as características dos verbos ficar e estar. No entanto, ao contrário das construções com esses verbos que representam só uma mudança de estado ou descrevem uma situação do momento, as construções deste grupo representam uma perma-

Fernanda

Beatriz

Caricari de

Moraes

\section{Leila Barbara}

$$
\text { nência, uma continuidade. }
$$

No corpus de estudo, apenas o verbo - manter, quando ligado ao clítico se, tem significado de permanecer. A maioria das ocorrências desse verbo possui significado relacional, como se pode observar abaixo:

50) Esse traço mantém-se relevante mesmo nos casos de antecedentes com o traço [-animado] ... (Idg021).

51) A segunda fase é a de sustentação labial. É nessa fase que o sorriso se mantém dependente do estímulo. (odrdpv15.9).

52) O conteúdo relativo de água manteve-se praticamente constante nos primeiros sete dias... (25975).

Nas ocorrências acima, o clítico se ligado ao verbo manter permite a interpretação relacional com significado de permanecer. Os Atributos relevante, dependente e constante avaliam os Portadores, contribuindo para a descrição do objeto de estudo (51 e 52) e dos resultados obtidos no experimento (53).

\section{5 Agnatos com se com significado de acontecer/ocorrer}

Neste subitem, são analisadas as construções que ocorrem no corpus com significado existencial de acontecer/ocorrer. Os verbos que, com o clítico se, possuem esse significado são: realizar, manifestar, dar e estabelecer, organizados quantitativamente no Quadro 5.

\begin{tabular}{|l|l|l|l|l|l|l|l|l|l|l|}
\hline Verbo & \multicolumn{2}{|l|}{$\begin{array}{l}\text { Existen- } \\
\text { ciais }\end{array}$} & \multicolumn{2}{l|}{$\begin{array}{l}\text { Relacio- } \\
\text { nais }\end{array}$} & \multicolumn{2}{l|}{ 2(E e R) } & \multicolumn{2}{l|}{$\begin{array}{l}\text { Desfoca- } \\
\text { mento }\end{array}$} & \multicolumn{2}{l|}{ Total } \\
\cline { 2 - 11 } & N & $\mathbf{\%}$ & N & $\mathbf{\%}$ & N & $\mathbf{\%}$ & N & $\mathbf{\%}$ & N & $\mathbf{\%}$ \\
\hline $\begin{array}{l}\text { Reali- } \\
\text { zar }\end{array}$ & 173 & 31 & 0 & 0 & 0 & 0 & 385 & 69 & $\mathbf{5 5 8}$ & $\mathbf{1 0 0}$ \\
\hline Dar & 225 & 45 & 4 & 0,5 & 145 & 29 & 127 & 25,5 & $\mathbf{5 0 1}$ & $\mathbf{1 0 0}$ \\
\hline $\begin{array}{l}\text { Mani- } \\
\text { festar }\end{array}$ & 124 & 76,5 & 0 & 0 & 0 & 0 & 38 & 23,5 & $\mathbf{1 6 2}$ & $\mathbf{1 0 0}$ \\
\hline
\end{tabular}




\begin{tabular}{|l|l|l|l|l|l|l|l|l|l|l|}
\hline $\begin{array}{l}\text { Estabe- } \\
\text { lecer }\end{array}$ & 24 & 22 & 0 & 0 & 0 & 0 & 86 & 78 & $\mathbf{1 1 0}$ & $\mathbf{1 0 0}$ \\
\hline Total & $\mathbf{5 4 6}$ & $\mathbf{4 1}$ & $\mathbf{4}$ & $\mathbf{0 , 3}$ & $\mathbf{1 4 5}$ & $\mathbf{1 0 , 7}$ & $\mathbf{6 3 6}$ & $\mathbf{4 8}$ & $\mathbf{1 3 3 1}$ & $\mathbf{1 0 0}$ \\
\hline
\end{tabular}

Quadro 5: Agnatos com se e significado de acontecer/ocorrer.

Nos artigos, as ocorrências dos verbos realizar, manifestar e estabelecer têm por função discutir aspectos teóricos, descrevendo-os como ocorrem:

53) ... na medida em que a primeira [sublimação (repressiva) da seUm uso muito xualidade] se estabelece no contexto de uma sociedade repressiparticular do va e a segunda numa sociedade transformada. (25430).

54) Essa tendência [globalização] manifesta-se, também, na difusão de padrões de organização econômica e social... (meioamb013).

55) $O$ ato de intelecção realiza-se sem cessar. É difícil dizer onde começa e onde termina o esforço intelectual. (25354).

56) .... a decomposição de matéria orgânica se realiza intensamente (Silva, 2002). (ensebsn).

Pode-se notar que os verbos acompanhados do clítico se, nas ocorrências acima, possuem significado de acontecer/ocorrer, sendo que o participante Existente localiza-se à esquerda do verbo e à direita circunstâncias de lugar (em 54) e modo (em 56 e 57). Pode-se pensar que essas ocorrências são construções passivas, porém o significado seria diferente, pois em uma construção passiva, mesmo com o participante omitido (Ator, Dizente, Existente, etc.), se supõe que aquela ação foi feita por um participante humano. Para Said Ali (1966/2008, p. 116), admitir o sentido passivo é admitir a possibilidade de um agente tanto oculto como expresso.

Ao contrário das orações materiais em que um agente age sobre um objeto, o Ator age sob a Meta, as orações existenciais anunciam a existência de algo. Thompson (1996, p. 101), no caso do inglês, discute que as orações existenciais, em geral, têm o verbo ser, porém os outros verbos que comumente ocorrem são diferentes de atributivos ou identificadores. A construção mais comum é com there, que não tem uma função representacional, mas é necessária como um Sujeito.

Assim como no inglês, em português, em orações deste tipo, o falante renuncia à oportunidade de se representar nos acontecimentos. É uma característica distintiva estrutural que promove um sinal de re- 
núncia, podendo ser visto como um recurso do autor apenas observar, em vez de participar do fluxo informacional do texto. É o caso de orações como 54 de duas maneiras - como uma construção existencial ou passiva.

Há construções com dar que ocorrem com o clítico se com signi-

Fernanda

Beatriz

Caricari de

Moraes

Leila Barbara

57) ... passa a sofrer o processo de gramaticalização, a exemplo do que se deu no francês. (Idg054).

58) Contrariamente ao que se deu com a privatização.... a argumentação constrói uma imagem negativa das manifestações, o que se pode observar nos seguintes recursos... (Idg046).

59) Ademais, o acesso à base material necessária à constituição da estrutura industrial não se deu livremente no mercado internacional,... (econ42).

Nota-se que nas construções acima não há a preposição por nem nominalizações como as anteriores. Pode-se notar, nessas ocorrências, a presença de apenas um participante, o Existente (processo de gramaticalização, privatização e o acesso). Nota-se que não se pode fazer refraseamentos com outros verbos existenciais e nem com relacionais, apenas com o existencial ocorrer:

60'. Ademais, o acesso à base material necessária à constituição da estrutura industrial não ocorreu livremente no mercado internacional...

Construções como as acima são utilizadas para representar uma existência, por isso seu significado existencial.

\subsection{Agnatos com se com significado de haver/existir}

A maioria das ocorrências de encontrar (91,3\%) é utilizada em construções relacionais, com significado de estar e, conforme foi mostrado anteriormente nesta seção de análise, são utilizadas para caracterizar e avaliar os resultados obtidos na pesquisa.

No entanto, há uma pequena parte das ocorrências de encontrar que pode ter significado existencial, o que corresponde a $6.3 \%$. Pode-se observar, nas ocorrências abaixo, o significado existencial que esse 
verbo possui:

60) Em N. Leite (1994) encontra-se uma discussão interessante utilizando essa categorização. (Idg087).

61) Em Nietzsche não se encontra a tensão entre o racional e o irracional... (25467).

62) Na Biblioteca da Pós-graduação em História, Antropologia e Ciência Política da UFF, encontra-se um livro pouco conhecido do público brasileiro... (25205).

Um uso muito particular do

Nos exemplos acima, encontrar tem significado de haver ou existir e representa a existência de algo, nesses casos - uma discussão, a tensão e um livro. Como se pode observar, os refraseamentos aceitam tanto o clítico se significado de haver como o de existir:

Os primeiros itens das orações acima: em N. Leite (1994), em Nietzsche e na Biblioteca da Pós-graduação em História, Antropologia e Ciência Política da UFF são consideradas circunstâncias de lugar.

O mesmo ocorre com o verbo ter que sem o clítico se funciona como relacional, porém, com esse clítico, pode ter significado de haver. Das ocorrências totais, apenas $12 \%$ possui esse significado:

63) No diagrama 1, tem-se uma forma de ocupação monocêntrica, enquanto no 2 existem diversos núcleos separados espacialmente. (m.amb18).

64) Na Figura 1 tem-se a estrutura do corante amaranto e a do corante azul brilhante. (eng.san6).

65) Mas no infinitivo latino tinha-se o radical [fatš] e no particípio [fak]. (Idg072).

As circunstâncias (lugar), assim como nas ocorrências anteriores, são os primeiros itens das orações que possuem apenas um participante - o Existente. Essas orações são utilizadas para apresentar elementos gráficos (diagrama, figura, quadro, etc.) e discutir aspectos teóricos da pesquisa.

No quadro abaixo, há uma síntese dos diferentes usos e significados desse grupo de verbos descrito neste artigo com base nas ocorrências do corpus de estudo: 


\begin{tabular}{|c|c|c|c|c|c|c|c|c|}
\hline \multirow{4}{*}{$\begin{array}{r}\text { Fernanda } \\
\text { Beatriz } \\
\text { Caricari de } \\
\text { Moraes }\end{array}$} & \multicolumn{2}{|l|}{$\begin{array}{l}\text { Significados/ } \\
\text { Verbos/Usos }\end{array}$} & 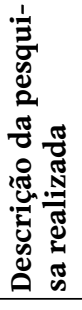 & 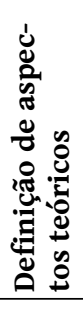 & 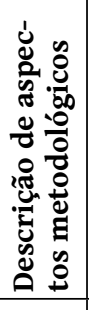 & 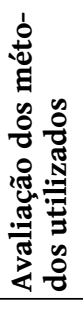 & 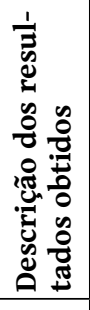 & 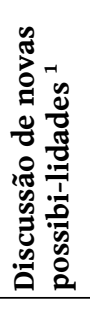 \\
\hline & \multirow{5}{*}{ Ser } & Fazer & $\mathrm{X}$ & & & & & \\
\hline & & Dar & & $\mathrm{X}$ & $\mathrm{X}$ & & & \\
\hline & & Tratar & $\mathrm{X}$ & $\mathrm{X}$ & $\mathrm{x}$ & $\mathrm{X}$ & & \\
\hline \multirow{3}{*}{ Leila Barbara } & & Apresentar & & & $\mathrm{x}$ & $\mathrm{X}$ & $\mathrm{X}$ & \\
\hline & & Mostrar & & & & & $\mathrm{X}$ & \\
\hline & \multirow{3}{*}{ Estar } & Encontrar & & & $\mathrm{X}$ & & $\mathrm{x}$ & \\
\hline \multirow[t]{10}{*}{254} & & Achar & $\mathrm{X}$ & & & & $\mathrm{X}$ & \\
\hline & & Fazer & & & & & & $\mathrm{X}$ \\
\hline & Ficar & Tornar & $\mathrm{X}$ & & $\mathrm{X}$ & & $\mathrm{X}$ & $\mathrm{X}$ \\
\hline & Permanecer & Manter & $\mathrm{X}$ & & & & $\mathrm{X}$ & \\
\hline & \multirow{4}{*}{ Ocorrer } & Realizar & & $\mathrm{X}$ & & & & \\
\hline & & Manifestar & & $\mathrm{X}$ & & & $\mathrm{x}$ & \\
\hline & & Dar & & $\mathrm{x}$ & $\mathrm{X}$ & $\mathrm{X}$ & & \\
\hline & & Estabelecer & & $\mathrm{X}$ & & & $\mathrm{x}$ & \\
\hline & \multirow{2}{*}{ Haver } & Encontrar & & $\mathrm{X}$ & & & & \\
\hline & & Ter & & $\mathrm{X}$ & & & & \\
\hline
\end{tabular}

Quadro 3: Síntese dos usos das construções ágnatas em artigos científicos.

\section{Considerações finais}

O arcabouço teórico e metodológico da Linguística Sistêmico-Funcional permitiu descrever e analisar os usos do se em artigos científicos produzidos em uma situação real de comunicação. 0 ambiente situacional e cultural foram levados em conta na análise das escolhas gramaticais feitas nos textos. O instrumento computacional utilizado, o programa WordSmith Tools (SCOTT, 2009), possibilitou o trabalho com uma grande quantidade de textos, fornecendo dados estatísticos e organizando-os a partir do item selecionado se para um estudo sistemático e minucioso de cada ocorrência e dos contextos em que estão inseridas.

A proposta de análise apresentada, neste artigo, permitiu descrever os usos do se, mostrando que seus usos não estão restritos a diferenciação entre índice de indeterminação do sujeito ou partícula apassiva- 
dora - considerada uma das grandes dificuldades dos usuários da língua portuguesa. Seus usos podem criar agnatos, isto é, um novo significado (relacional e/ou existencial) pode ser criado quando o clítico se ocorre em determinados contextos com certos tipos de verbos. Essas construções mudam o status do verbo e da relação entre os participantes da oração.

Nos artigos, essas construções são utilizadas para justificar a importância de sua pesquisa e/ou de pesquisas futuras; identificar do tipo de pesquisa realizada, definir de aspectos teóricos; avaliar etapas feitas na pesquisa ou métodos utilizados; descrever aspectos metodológicos e resultados obtidos; discutir novas possibilidades de pesquisa e delimitações e descrever que algo acontece ou aconteceu, em geral, um fato ou um objeto relacionado com a pesquisa.

Espera-se que esta análise possa ser utilizada no ensino de escriUm uso muito particular do clíticose

ta acadêmica ou, até mesmo, adaptada para o uso nas escolas de Ensino Fundamental e Médio, propondo uma reflexão dos usos do se com base em exemplos reais de gêneros conhecidos pelos alunos.

\section{Referências}

BAGNO, M. A “subversão herética” do ensino de língua. In: Bagno, M. Dramática da Língua Portuguesa: tradição gramatical, mídia e exclusão social. São Paulo: Loyola. pp. 219-250, 2000.

AUTOR1. In: Autor1. (org). 2010.

AUTOR2. In: Autor1. 2011.

CAFFAREL, A. A systemic functional grammar of French. Londres: Continuum, 2006

CAMACHO, R. G. Construções de voz. In: Abarirre, M. B. \& Rodrigues, S. C. A. (org). Gramática do português falado. Campinas: Editora Unicamp, vol. 8, pp. 227-316, 2002. . Em defesa da categoria de voz média no Português. D.E.L.T.A., vol. 19.1, pp. 91-122, 2003. 
CINQUE, G. On si constructions and the theory of Arb. Linguistics inquiry, v. 19, pp. 521-581, 1988.

EGGINS, S. An introduction to Systemic Functional Linguistics. Londres:Pinter Publishers, 1994.

Fernanda

Beatriz

GIVÓN, T. On understand grammar. New York: Academic Press, 1981.

Caricari de

Moraes . Voice and inversion. Amsterdã: John Benjamins, 1994.

Leila Barbara

HALLIDAY, M.A.K. An Introduction to Functional Grammar. London: E. Arnold, 1985.

An introduction to Functional Grammar. London: Edward Arnold, 1994.

HALLIDAY, M. A. K. \& MATTHIESSEN, C.M.I.M. An introduction to Functional Grammar. London: Edward Arnold. Third Edition, 2004.

MARTIN, J.R. Context: register, genre and ideology. English text -systems and structure. Philadelphia/Amsterdam: John Benjamins Publishing Company, 1992.

MATTHIESSEN, C.M.I.M. Lexicogrammatical cartography: English systems. Tokyo: International Language Science Publishers, 1995.

MONTEIRo, J. L. A questão do se. In: Monteiro, J. L. Pronomes pessoais: subsídios para uma gramática do português do Brasil. Fortaleza, EUFC, 1994.

NUNES, J. Se apassivador e se indeterminador: o percurso diacrônico no português brasileiro. Caderno de Estudos Linguísticos. pp. 33-59, 1991.

RUWET, N. Les constructions pronominales neutres et moyennes. Théorie syntaxique et syntaxe du français. Paris: Seuil, 1972. 
SAID ALI, M. Dificuldades da língua portuguesa. Rio de Janeiro: Biblioteca Nacional. $1^{\text {a }}$ ed., 1966.

SAYÃO, J. o jornalismo literário e as falas de seus entrevistados: um estudo de linguística sistêmico-funcional. Dissertação de Mestrado.PUC-SP, 2011.

SCOTT, M. R. Wordsmith Tools versão 5.0. Software for text analysis. Oxford: Oxford University Press, 2009.

Um uso muito particular do

SUÑER, M. Las passives con se impessoal y la legitimación de las categoclítico se rias vacías. In: Lopes, C. S. Las construciones com se. Madri: Visor libros, 2002.

THOMPSON, G. Introducing functional grammar. Londres: Arnold, 1996.

TORRES, F.F.G. A construção da identidade marginal no livro "Graduado em Marginalidade": a Linguística Sistêmico-Funcional como ferramenta aos estudos críticos. Dissertação de Mestrado. PUC-SP, 2012.

VIVAN, E. Principais usos de processos verbais e metáforas interpessoais em artigos de linguística aplicada. Tese de doutorado. PUC-SP, 2010. 
